\title{
The origin of transverse anisotropy in axially symmetric Single Molecule Magnets
}

Anne Laure Barra, Andrea Caneschi, Andrea Cornia, Dante Gatteschi, * Lapo Gorini, Leo-Philipp Heiniger, Roberta Sessoli amd Lorenzo Sorace

\section{$\underline{\text { Supplementary Information }}$}

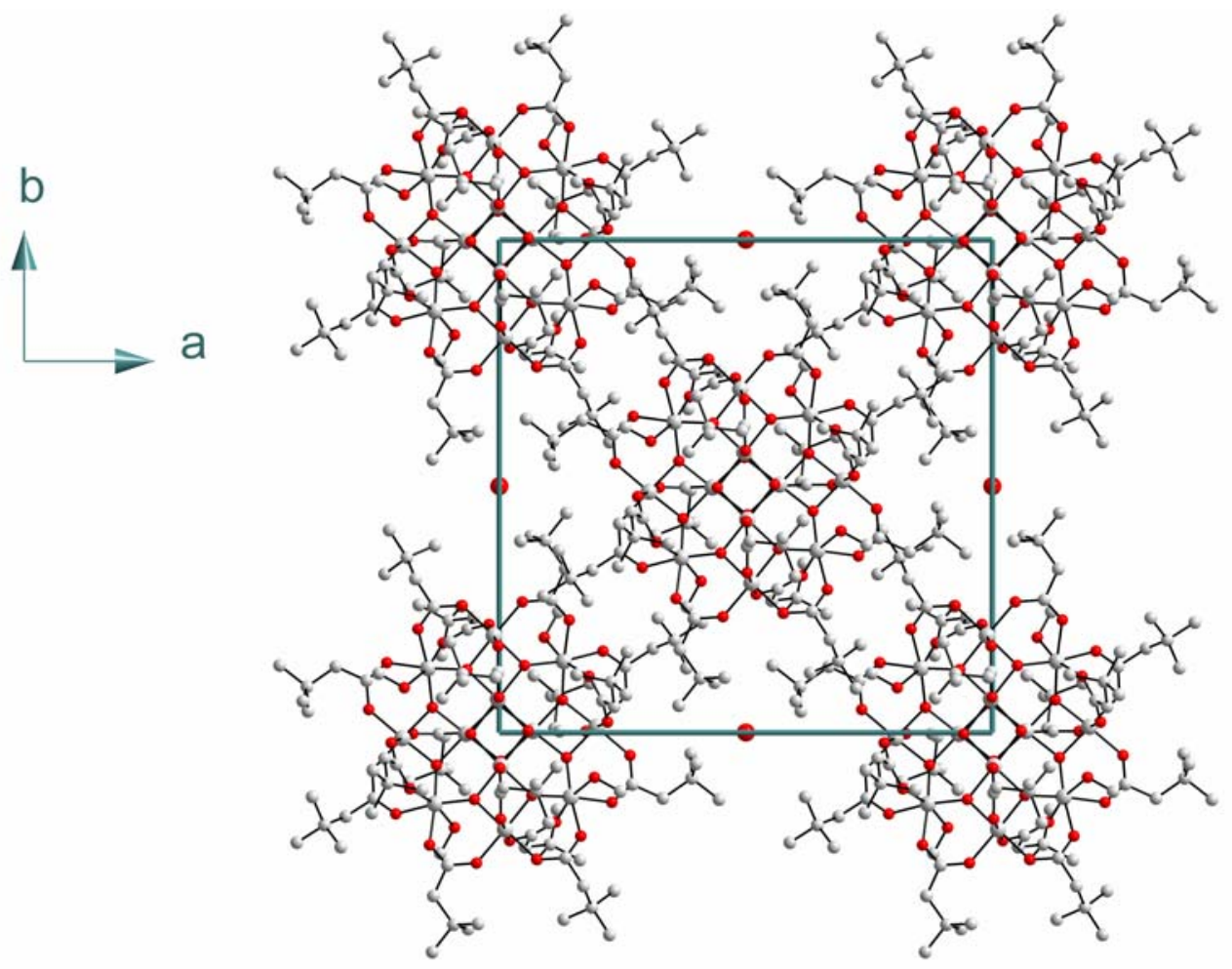

Figure S1. Diamond plot of the crystal packing in Mn12tBuAc viewed along the $c$ axis. Oxygen atoms are red. Only the oxygen atoms of the methanol solvent molecules are shown. 
Table S1. Selected Bond lengths $[\AA]$ and angles $\left[{ }^{\circ}\right]$ for $\mathbf{1}$

\begin{tabular}{|c|c|c|c|}
\hline $\mathrm{Mn}(1)-\mathrm{O}(2)$ & $1.868(4)$ & $\mathrm{O}(2)-\mathrm{Mn}(1)-\mathrm{O}(3)$ & $84.67(18)$ \\
\hline $\mathrm{Mn}(1)-\mathrm{O}(3)$ & $1.874(4)$ & $\mathrm{O}(4)-\mathrm{Mn}(1)-\mathrm{O}(1) \# 2$ & $93.67(19)$ \\
\hline $\mathrm{Mn}(1)-\mathrm{O}(4)$ & $1.897(4)$ & $\mathrm{O}(1)-\mathrm{Mn}(1)-\mathrm{O}(1) \# 1$ & $84.66(17)$ \\
\hline $\mathrm{Mn}(1)-\mathrm{O}(1)$ & $1.911(4)$ & $\mathrm{O}(3)-\mathrm{Mn}(1)-\mathrm{O}(1) \# 2$ & $172.52(17)$ \\
\hline $\mathrm{Mn}(1)-\mathrm{O}(1) \# 1$ & $1.915(4)$ & $\mathrm{O}(4)-\mathrm{Mn}(1)-\mathrm{O}(1)$ & $176.08(19)$ \\
\hline $\mathrm{Mn}(1)-\mathrm{O}(1) \# 2$ & $1.935(4)$ & $\mathrm{O}(2)-\mathrm{Mn}(1)-\mathrm{O}(1) \# 1$ & $175.26(17)$ \\
\hline $\mathrm{Mn}(2)-\mathrm{O}(2)$ & $1.883(4)$ & $\mathrm{O}(11)-\mathrm{Mn}(2)-\mathrm{O}(8)$ & $82.6(2)$ \\
\hline $\mathrm{Mn}(2)-\mathrm{O}(3) \# 2$ & $1.902(4)$ & $\mathrm{O}(2)-\mathrm{Mn}(2)-\mathrm{O}(3) \# 2$ & $93.79(17)$ \\
\hline $\mathrm{Mn}(2)-\mathrm{O}(11)$ & $1.971(5)$ & $\mathrm{O}(2)-\mathrm{Mn}(2)-\mathrm{O}(7)$ & $95.14(18)$ \\
\hline $\mathrm{Mn}(2)-\mathrm{O}(8)$ & $1.976(5)$ & $\mathrm{O}(3) \# 2-\mathrm{Mn}(2)-\mathrm{O}(7)$ & $95.70(19)$ \\
\hline $\mathrm{Mn}(2)-\mathrm{O}(7)$ & $2.122(5)$ & $\mathrm{O}(8)-\mathrm{Mn}(2)-\mathrm{O}(7)$ & $88.8(2)$ \\
\hline $\mathrm{Mn}(2)-\mathrm{O}(12)$ & $2.223(5)$ & $\mathrm{O}(11)-\mathrm{Mn}(2)-\mathrm{O}(7)$ & $84.5(2)$ \\
\hline $\mathrm{Mn}(3)-\mathrm{O}(3)$ & $1.888(4)$ & $\mathrm{O}(2)-\mathrm{Mn}(2)-\mathrm{O}(12)$ & $93.14(18)$ \\
\hline $\mathrm{Mn}(3)-\mathrm{O}(2)$ & $1.895(4)$ & $\mathrm{O}(3) \# 2-\mathrm{Mn}(2)-\mathrm{O}(12)$ & $92.26(18)$ \\
\hline $\mathrm{Mn}(3)-\mathrm{O}(10) \# 1$ & $1.931(4)$ & $\mathrm{O}(11)-\mathrm{Mn}(2)-\mathrm{O}(12)$ & $86.4(2)$ \\
\hline $\mathrm{Mn}(3)-\mathrm{O}(9)$ & $1.948(5)$ & $\mathrm{O}(8)-\mathrm{Mn}(2)-\mathrm{O}(12)$ & $82.4(2)$ \\
\hline $\mathrm{Mn}(3)-\mathrm{O}(6)$ & $2.148(5)$ & $\mathrm{O}(7)-\mathrm{Mn}(2)-\mathrm{O}(12)$ & $168.10(19)$ \\
\hline $\mathrm{Mn}(3)-\mathrm{O}(5)$ & $2.170(5)$ & $\mathrm{O}(2)-\mathrm{Mn}(2)-\mathrm{O}(11)$ & $174.30(19)$ \\
\hline $\operatorname{Mn}(1)-\operatorname{Mn}(3)$ & $2.7726(14)$ & $\mathrm{O}(3) \# 2-\mathrm{Mn}(2)-\mathrm{O}(8)$ & $172.52(19)$ \\
\hline $\operatorname{Mn}(1)-M n(1) \# 1$ & $2.8269(17)$ & $\mathrm{O}(3)-\mathrm{Mn}(3)-\mathrm{O}(2)$ & $83.54(17)$ \\
\hline $\operatorname{Mn}(1)-M n(1) \# 2$ & $2.8269(17)$ & $\mathrm{O}(10) \# 1-\mathrm{Mn}(3)-\mathrm{O}(9)$ & $85.70(19)$ \\
\hline $\operatorname{Mn}(1)-\operatorname{Mn}(1) \# 3$ & $2.9219(19)$ & $\mathrm{O}(2)-\mathrm{Mn}(3)-\mathrm{O}(6)$ & $92.96(18)$ \\
\hline $\mathrm{Mn}(1)-\mathrm{O}(1)-\mathrm{Mn}(1) \# 2$ & $95.28(17)$ & $\mathrm{O}(3)-\mathrm{Mn}(3)-\mathrm{O}(6)$ & $95.14(18)$ \\
\hline $\mathrm{Mn}(1)-\mathrm{O}(1)-\mathrm{Mn}(1) \# 1$ & $94.61(17)$ & $\mathrm{O}(9)-\mathrm{Mn}(3)-\mathrm{O}(6)$ & $89.7(2)$ \\
\hline $\mathrm{Mn}(1) \# 2-\mathrm{O}(1)-\mathrm{Mn}(1) \# 1$ & $98.74(16)$ & $\mathrm{O}(10) \# 1-\mathrm{Mn}(3)-\mathrm{O}(6)$ & $88.7(2)$ \\
\hline $\mathrm{Mn}(1)-\mathrm{O}(2)-\mathrm{Mn}(2)$ & $134.0(2)$ & $\mathrm{O}(3)-\mathrm{Mn}(3)-\mathrm{O}(5)$ & $85.90(17)$ \\
\hline $\mathrm{Mn}(1)-\mathrm{O}(2)-\mathrm{Mn}(3)$ & $94.89(17)$ & $\mathrm{O}(2)-\mathrm{Mn}(3)-\mathrm{O}(5)$ & $87.70(18)$ \\
\hline $\mathrm{Mn}(2)-\mathrm{O}(2)-\mathrm{Mn}(3)$ & $124.1(2)$ & $\mathrm{O}(10) \# 1-\mathrm{Mn}(3)-\mathrm{O}(5)$ & $90.7(2)$ \\
\hline $\mathrm{Mn}(1)-\mathrm{O}(3)-\mathrm{Mn}(3)$ & $94.95(18)$ & $\mathrm{O}(9)-\mathrm{Mn}(3)-\mathrm{O}(5)$ & $89.3(2)$ \\
\hline $\mathrm{Mn}(1)-\mathrm{O}(3)-\mathrm{Mn}(2) \# 1$ & $132.9(2)$ & $\mathrm{O}(2)-\mathrm{Mn}(3)-\mathrm{O}(10) \# 1$ & $177.65(19)$ \\
\hline $\mathrm{Mn}(3)-\mathrm{O}(3)-\mathrm{Mn}(2) \# 1$ & $128.9(2)$ & $\mathrm{O}(3)-\mathrm{Mn}(3)-\mathrm{O}(9)$ & $175.2(2)$ \\
\hline $\operatorname{Mn}(3)-\operatorname{Mn}(1)-\operatorname{Mn}(1) \# 3$ & $178.33(5)$ & $\mathrm{O}(6)-\mathrm{Mn}(3)-\mathrm{O}(5)$ & $178.83(19)$ \\
\hline
\end{tabular}

Symmetry transformations used to generate equivalent atoms:

\#1 y,-x,-z+2 \#2 -y,x,-z+2 \#3 -x,-y,z \#4 -y+1/2,x+1/2,-z+3/2 \#5 y-1/2,-x+1/2,-z+3/2 \#6 -x,-y+1,z 


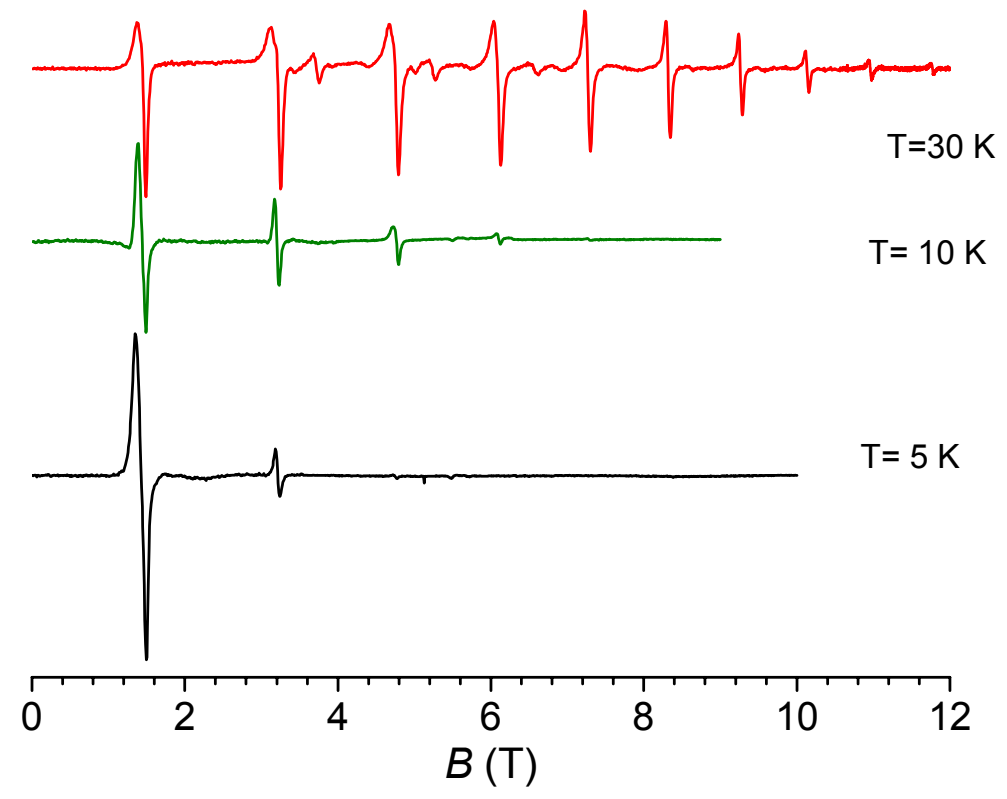

Figure S2. Temperature dependence of the HFEPR spectra measured at $345 \mathrm{GHz}$ with the scanning field parallel to the $c$ crystallographic axis. 

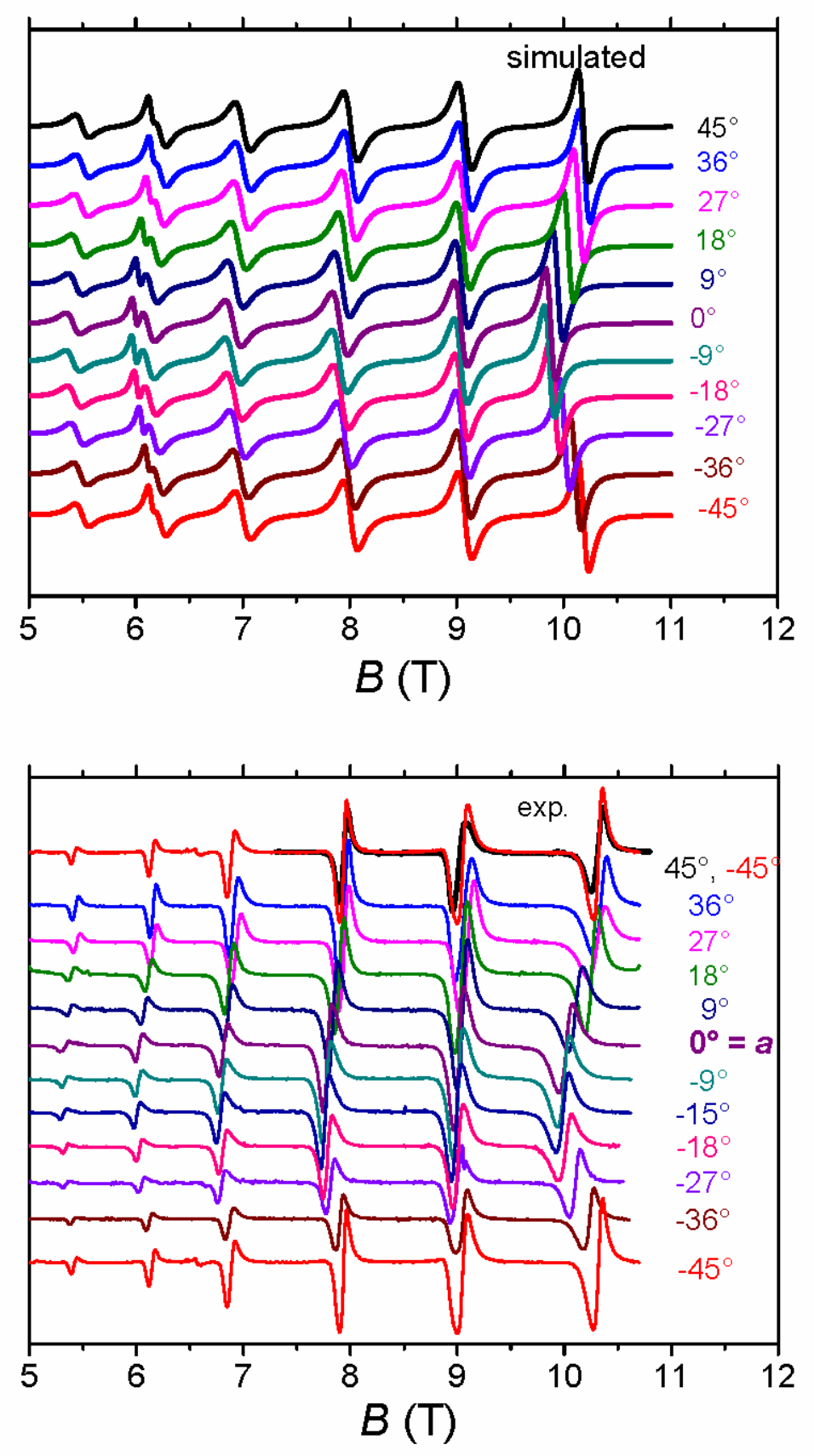

Figure S3. Top) Calculated angular dependence of the HFEPR spectra at $115 \mathrm{GHz}$ and $\mathrm{T}=5 \mathrm{~K}$ with the best fit parameters: $\mathrm{g}_{/ /}=2.00, \mathrm{~g} \perp=1.93, D=-0.459(1) \mathrm{cm}^{-1}, B_{4}{ }^{0}=-2.34(4) \times 10^{-5} \mathrm{~cm}^{-1}, B_{6}{ }^{0}=-1.0$ $(2) \times 10^{-8} \mathrm{~cm}^{-1}, B_{4}{ }^{4}=+2.0(2) \times 10^{-5} \mathrm{~cm}^{-1}$, and $B_{6}{ }^{4}=-1.0(1) \times 10^{-7} \mathrm{~cm}^{-1}$. Bottom) Experimental spectra. 


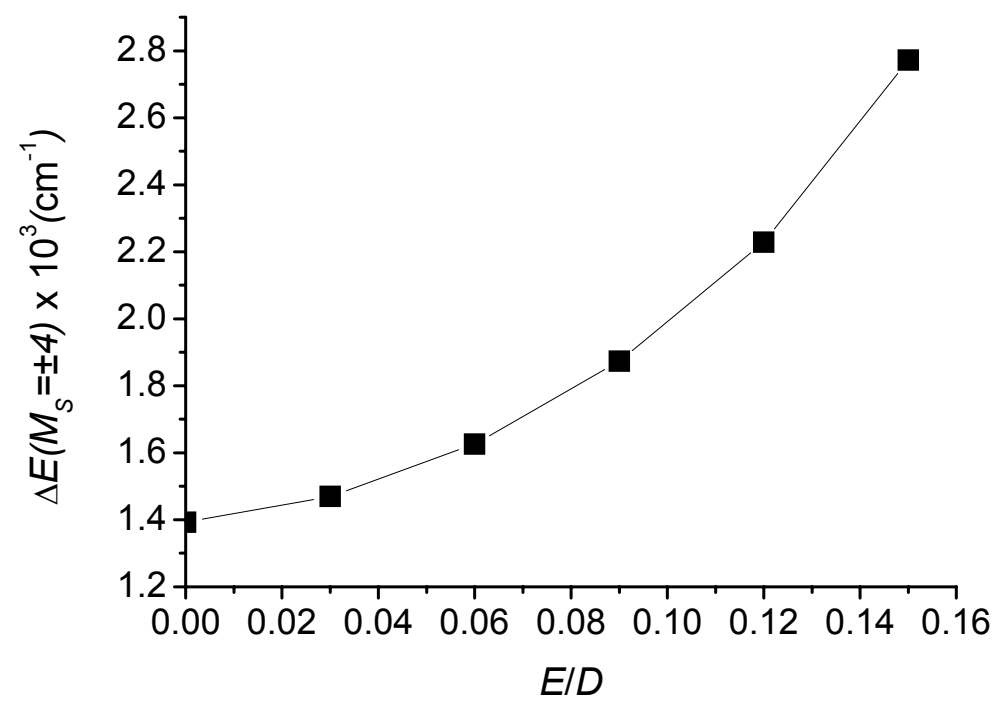

Figure S4. Dependence of the energy splitting $\Delta E$ of the formally $M_{s}= \pm 4$ pair as a function of the rhombic anisotropy $E$ of the external $s=2$ spins for the five spin model. The other parameters have been fixed to the values mentioned in the text.

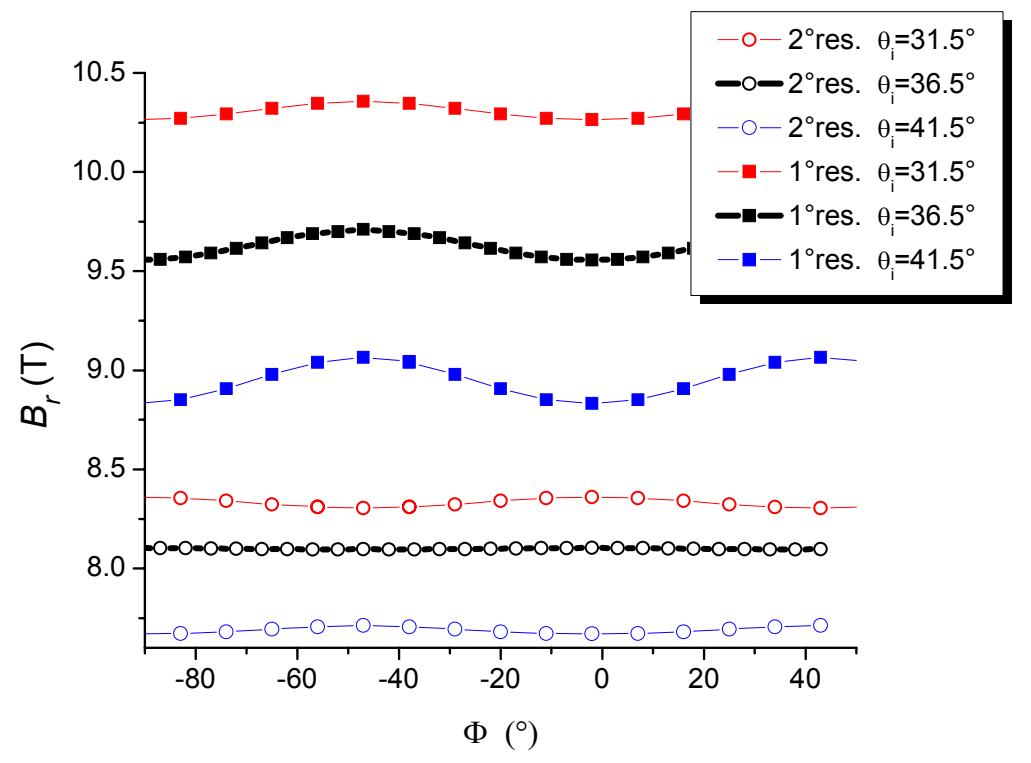

Figure S5. Calculated angular dependence of the resonance fields in $115 \mathrm{GHz}$ HF-EPR experiments with the sweeping field applied in the $a b$ plane. A Multi Spin Hamiltonian based on five interacting spins had been employed and the tilting angle $\theta$ of the local easy axes is varied by $\pm 5^{\circ}$ compared to the value $\left(36.5^{\circ}\right)$ determined from the X-ray crystal structure determination of $\mathrm{Mn} 12 t \mathrm{BuAc}$. Only the first and second highest field transitions are shown. 
Table S2. Best fit parameters of the Spin Hamiltonian (1) used to reproduce the angular dependence of the resonance fields of Figure S5, calculated with the multi-spin Hamiltonian (8) for three different values of the tilting angle, $\theta$, of the $\mathrm{Mn}^{\mathrm{III}}$ (site 2 ) elongation axes. All values are reported in $\mathrm{cm}^{-1}, g_{x}=g_{y}=1.93$, and $g_{z}=2.00$.

\begin{tabular}{|l|c|c|c|c|c|}
\hline & $D$ & $B_{4}{ }^{0}$ & $B_{4}{ }^{0}$ & $B_{4}{ }^{4}$ & $B_{6}{ }^{4}$ \\
\hline$\theta=31.5^{\circ}$ & $-4.38 \mathrm{E}-001$ & $-2.6 \mathrm{E}-006$ & $-3.6 \mathrm{E}-008$ & $3.9 \mathrm{E}-006$ & $-3.3 \mathrm{E}-008$ \\
\hline$\theta=36.5^{\circ}$ & $-3.92 \mathrm{E}-001$ & $-1.5 \mathrm{E}-006$ & $-2.9 \mathrm{E}-008$ & $7.5 \mathrm{E}-006$ & $-4.2 \mathrm{E}-008$ \\
\hline$\theta=41.5^{\circ}$ & $-3.48 \mathrm{E}-001$ & $-3.9 \mathrm{E}-006$ & $-4.1 \mathrm{E}-008$ & $1.2 \mathrm{E}-005$ & $-5.1 \mathrm{E}-008$ \\
\hline
\end{tabular}




\section{Strong Field Limit calculations}

The Stevens' operators which describe the in-plane anisotropy up to the 6th order in an axial system with fourfold symmetry take the form:

$$
\begin{aligned}
& \hat{O}_{4}^{4}=\frac{1}{2}\left(\hat{S}_{+}^{4}+\hat{S}_{-}^{4}\right) \\
& \hat{O}_{6}^{4}=\frac{1}{4}\left[\left(11 \hat{S}_{z}^{2}-S(S+1)-38\right)\left(\hat{S}_{+}^{4}+\hat{S}_{-}^{4}\right)+\left(\hat{S}_{+}^{4}+\hat{S}_{-}^{4}\right)\left(11 \hat{S}_{z}^{2}-S(S+1)-38\right)\right]
\end{aligned}
$$

In order to highlight 4th- and 6th-order contributions, the relevant Hamiltonian is most conveniently re-written as

$$
\hat{\mathcal{H}}^{\prime}=B_{4}^{4} \hat{O}_{4}^{4}+B_{6}^{4} \hat{O}_{6}^{4}=\frac{1}{2} \varepsilon_{4}\left(\hat{S}_{+}^{4}+\hat{S}_{-}^{4}\right)+\frac{1}{4} \varepsilon_{6}\left[\hat{S}_{z}^{2}\left(\hat{S}_{+}^{4}+\hat{S}_{-}^{4}\right)+\left(\hat{S}_{+}^{4}+\hat{S}_{-}^{4}\right) \hat{S}_{z}^{2}\right]
$$

with

$$
\begin{aligned}
& \varepsilon_{4}=B_{4}^{4}-[S(S+1)+38] B_{6}^{4} \\
& \varepsilon_{6}=11 B_{6}^{4} .
\end{aligned}
$$

In general, when the magnetic field is applied in the $x y$ plane, each EPR resonance field shows a particular dependence ("modulation") on the angle $\phi$ between the scanning magnetic field and the $x$ axis. This results from a subtle balance between 4 th order $\left(\varepsilon_{4}\right)$ and 6 th order $\left(\varepsilon_{6}\right)$ contributions. the The basic mechanism which leads to resonance modulation as well as the combined effect of $\varepsilon_{4}$ and $\varepsilon_{6}$ can be appreciated by recurring to the strong-field approximation. In this case, the spin functions, $\mid m>$, are eigenfunctions of the spin component along the field direction $\mathbf{S}_{H}=\mathbf{S}_{x} \cos \phi+\mathbf{S}_{y} \sin \phi$ and can be written as linear combinations of the eigenfunctions of $\mathbf{S}_{z}, \mid M>$ :

$$
|m\rangle=\sum_{M} C_{m M}|M\rangle
$$

with $\phi$-dependent coefficients $C_{m M}=\langle m \mid M\rangle$. Once the $C_{m M}$ 's are known the first-order correction to the Zeeman levels can be very simply calculated and takes the form:

$$
\left\langle m\left|\hat{\mathcal{H}}^{\prime}\right| m\right\rangle=A_{m} \cos (4 \phi)
$$

Each level is thus found to exhibit the expected four-fold modulation with the $\phi$ angle.

The modulation amplitude $A_{m}$ is reported in Figure S6 as a function of $m$ for the levels from $m=-10$ to 0 of a $S=10$ multiplet in two limiting situations, namely $\varepsilon_{6}=0$ (4th-order anisotropy only) and $\varepsilon_{4}$ $=0$ (6th-order anisotropy only). The complete graph has mirror symmetry around $m=0$. It is clearly seen that the amplitude of 4th and 6th order corrections have in general a different dependence upon $m$. The $m$-dependence of the overall modulation is therefore determined by the particular values taken by the $\varepsilon_{4}$ and $\varepsilon_{6}$ coefficients. We now show how level modulation is linked to resonance modulation. In the strong-field limit, the Zeeman levels are simple linear functions of magnetic field:

$$
E_{m}=E_{m}^{0}+A_{m} \cos (4 \phi)+g \mu_{B} m H
$$


where $E_{m}{ }^{0}$ is the extrapolated zero-field energy of the $m$ substate determined by axial anisotropy terms (in the present case, $D, B_{4}^{0}$ and $B_{6}^{0}$ ). From the resonance condition $E_{m+1}-E_{m}=h v$ one obtains the resonance field $H_{r}$ as

$$
H_{r}=H_{r}^{0}+\frac{A_{m}-A_{m+1}}{g \mu_{B}} \cos (4 \phi)
$$

We conclude that, provided that $A_{m+1}$ and $A_{m}$ are different, $H_{r}$ for the transition $m \rightarrow m+1$ undergoes itself a four-fold $\phi$-modulation around $H_{r}{ }^{0}$, the resonance field uncorrected by transverse anisotropy terms. Furthermore, the "phase" of the modulation (i.e. the observation of an easy or of a hard direction at $\phi=0, \pi / 2$, etc.) is related to the sign of $A_{m}-A_{m+1}$. Depending on the values of $\varepsilon_{4}$ and $\varepsilon_{6}$ some transitions may accidentally exhibit no angular modulation. For instance, in order for the -9 $\rightarrow-8$ transition to have zero modulation amplitude, $A_{-9}$ and $A_{-8}$ must be equal, requiring $\varepsilon_{4}$ and $\varepsilon_{6}$ to have opposite signs with $\varepsilon_{6} / \varepsilon_{4}=-5 / 73$ (Figure S6). For positive $\varepsilon_{4}$, the resonance field for the transition $-10 \rightarrow-9$ is calculated to exhibit the largest modulation amplitude (largest $\left|A_{m}-A_{m+1}\right|$ ), and for this transition $\phi=0$ represents a "hard" magnetic direction $\left(A_{-10}-A_{-9}>0\right)$. As anticipated, the line $-9 \rightarrow-8$ becomes $\phi$-independent. The $\phi$-modulation is restored for all the subsequent transitions, because $A_{m}-A_{m+1} \neq 0$. Notice, however, that the transitions $-8 \rightarrow-7,-7 \rightarrow-6$ and $-6 \rightarrow-$ 5 have $A_{m}-A_{m+1}<0$, so that their modulation phase is reversed as compared with $-10 \rightarrow-9(\phi=0$ represents an "easy" magnetic direction for these lines).

A similar behavior is observed experimentally, although with some significant differences. The transition $-10 \rightarrow-9$ is found to undergo the largest modulation, as expected, but $-8 \rightarrow-7$ and $-7 \rightarrow-$ 6 have the same "phase" as $-10 \rightarrow-9$. This discrepancy disappears when the resonance fields are evaluated by numerical diagonalization of the spin-hamiltonian matrix, i.e. without recurring to the strong-field approximation.

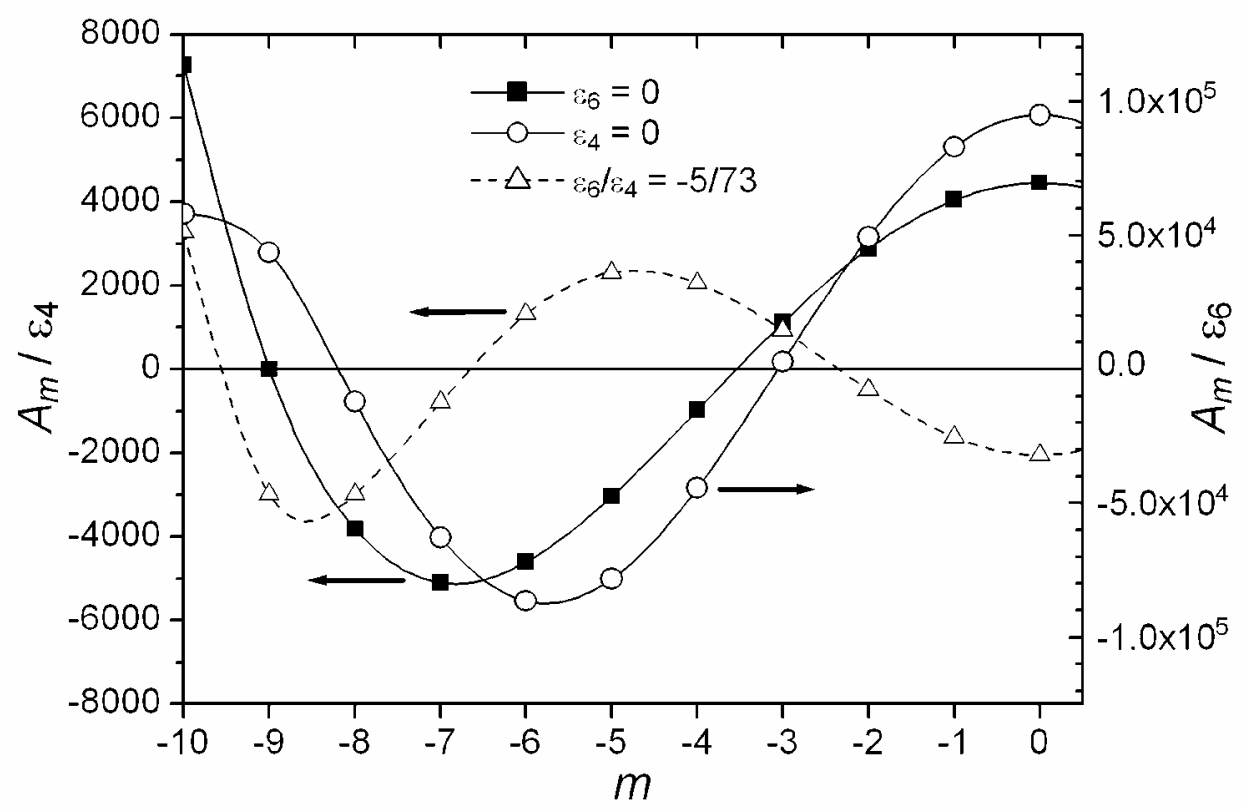

Figure S6. $\phi$-modulation amplitude of the $m$-levels when the magnetic field is directed in the $x y$ plane at an angle $\phi$ from the $x$ axis, as computed in the strong exchange limit for different values of the $\varepsilon_{4}$ and $\varepsilon_{6}$ parameters. 